and for the community at large. To let this potential role go by default would be a loss for British public discussion as well as a tragedy for the British Association.

But how is it possible to do ambitious things without a budget? This is what the accountants are bound to say. Undoubtedly there is much that could be done to turn this criticism by strictly business stratagems. At the same time, however, it is essential that means should be found for simplifying the association's constitution. The issue is not whether the sixteen sections into which the proceedings are divided should continue to exist, but whether there is some device for allowing the organization as a whole to act decisively when its own interests and those of its members call for something to be done. At the same time, ways must be found of convincing even busy working scientists that the association can do something to further the common cause of a healthy scientific community in an appreciative and responsive setting. In attempting all this, organization in the ordinary sense is much less important than publicity of the right kind, but everyone knows that to say as much will offend against the over-modest dissembling of the British Association's members. This is why it is to be hoped that the annual meeting in Swansea will find people prepared for the radical departures from past policy that the circumstances warrant.

\title{
The Next Step with Nuclear Explosions
}

THE French government has done the decent thing in bowing to public pressure and cancelling the series of nuclear explosions planned for the next few weeks in the atolls of the Tahiti group. For one thing, of course, it is intolerable that the government of France (like that of China) should continue to release large quantities of fall-out into the atmosphere without acknowledging that to do so is to create a public nuisance. This, after all, is a form of pollution that justifiably merits concern. Protests at the impending explosions from neighbouring regions in the Pacific may have helped to change the French government's course of action, but it is also probable that the time is coming when the Gaullist view of the utility of nuclear weapons is fading. It is a long time now since the strategic justification of the French independent nuclear force was argued with enthusiasm. For one thing, it has turned out to be a costly way of hoping to make sure that in the event of an aggression, it would be possible for the military forces of France "to tear an arm" off the enemy before sinking beneath a hail of nuclear explosions. Second, nuclear weapons seem increasingly irrelevant to the military problems of Europe, especially now that the gap between East and West has been bridged to some extent by the continuing civility of relations in central Europe and by the signature last week of the agreement between the Occupying Powers on the future of Berlin. Third, the French nuclear force tends to be a device within the framework of an increasingly united Europe (and the British nuclear force, now almost forgotten, would be equally an irritant if it were ever advertised). In short, the government of France would be well advised to wash its hands of nuclear weapons at this stage of the game. Enough has been done to show that the properties of nuclei are the same in France as elsewhere. Not nearly enough has been done to make use of them.

In these circumstances, the time has come rather to ask what arrangements will in future be made for regulating the uses made of nuclear weapons. It is getting on for a decade since the partial ban on nuclear tests was negotiated, and the International Atomic Energy Agency in Vienna is now up to its eyes-and some say buried-in the intricacies of policing that unsatisfactory agreement. In the year just ended, the agency took over responsibility for policing safeguards agreements at about a hundred nuclear installations. According to the annual report for the year just past, it spent a total of $\$ 1.7$ million on the work, and the budget for the coming year, also now published, suggests that this will rise to $\$ 2.6$ million in the next twelve months. As always, the agency's abiding problem in the implementation of the safeguards policy is the recruitment of sufficiently skilled people and the determination of the conditions under which they should work. Optimism at Vienna runs as high as ever, but it is hard for outsiders easily to accept that the agency would be able to police effectively safeguards for a world in which the number of nuclear power stations under its authority was counted not in tens but in thousands.

This is why it is heartening in the past few months that the subcommittee of the UN Assembly on Disarmament, meeting at Geneva, has taken up again the issue of extending the partial test-ban to include all experimental nuclear explosions, whether underground or in the air. Not merely would this device let the Vienna agency escape from the invidious position of policing the unpoliceable into which it has been jockeyed, but it would solve a host of other problems, from the proper balancing of risks and benefits in some of the newer developments of military technology-multiple nuclear warheads, for example. Moreover, an extension of the test-ban would help to ensure that the asymmetries incorporated in the present treaty, and which in particular allot privileged positions to countries which have already manufactured nuclear weapons for themselves, will not at some stage lead to demands among the non-nuclear powers that they too should have weapons to themselves. In this sense, the non-proliferation treaty remains what it has been since its conception (and what its preamble says it is)--a temporary expedient.

As it happens, technical developments are also favourable. The article on page 51 by Dr F. M. Anglin shows how it is now possible to discriminate more accurately than previously between earthquakes and nuclear explosions with less than the equivalent of 10,000 kilotons of energy. The idea (see page 8 ) is that even quite small explosions can be distinguished from earthquakes of comparable size by the high frequency parts of their seismic spectra. To be sure, nobody would pretend at this stage that all explosions can be distinguished unambiguously from naturally occurring earthquakes, but there has been an immense improvement in the technology of test detection and discrimination since the days when the nonproliferation treaty was first advanced. 